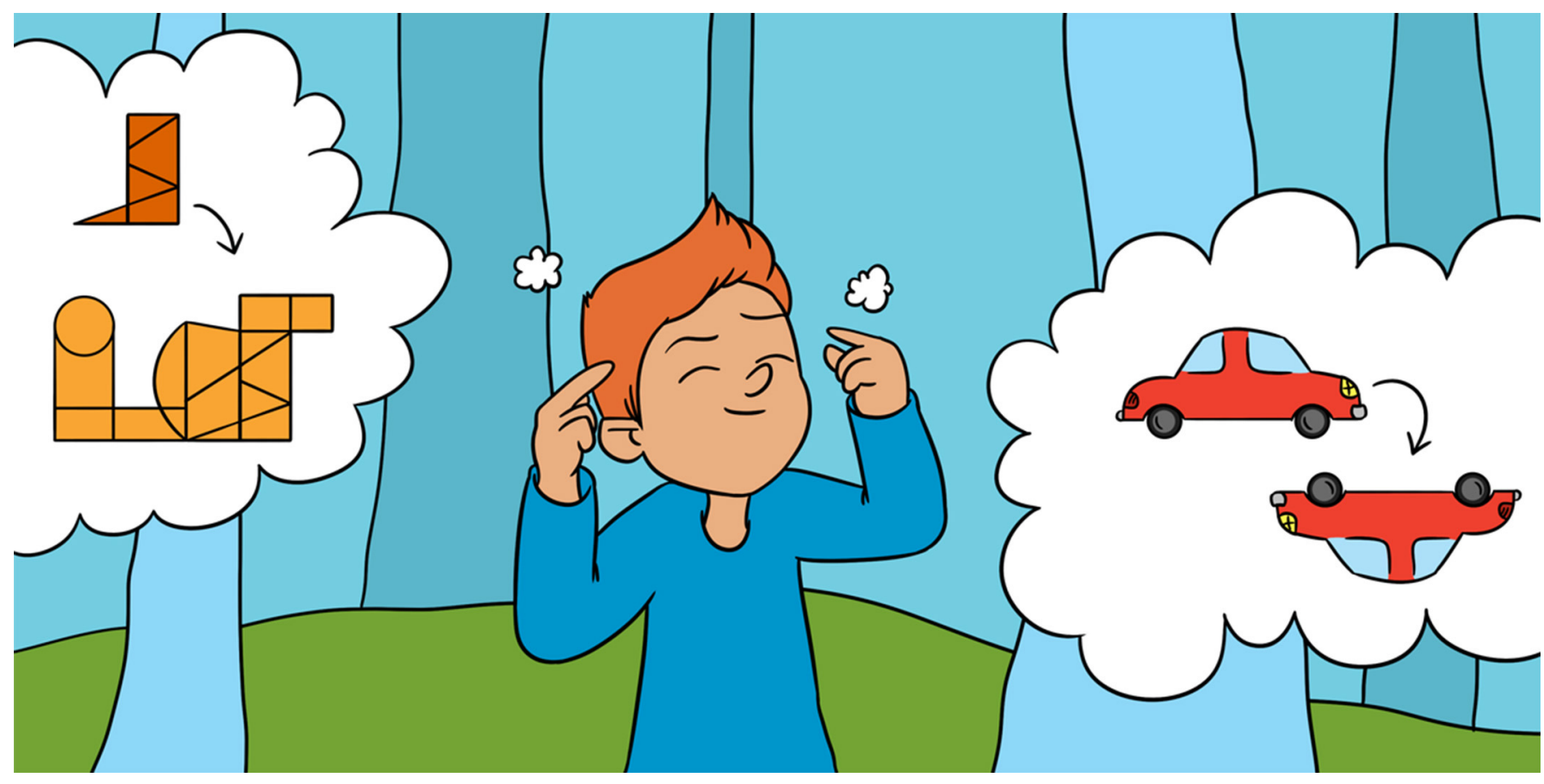

\title{
MAKE SPACE: THE IMPORTANCE OF SPATIAL THINKING FOR LEARNING MATHEMATICS
}

\section{Katie A. Gilligan *}

School of Psychology, University of Surrey, Guildford, United Kingdom

YOUNG REVIEWER:

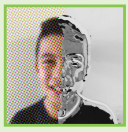

GONI

AGE: 11
Spatial thinking allows you to understand the location and dimension of objects, and how different objects are related. It also allows you to visualize and manipulate objects and shapes in your head. Not only is spatial thinking very important for everyday tasks, new research shows that it is essential for mathematics learning. Children and teenagers who are good at spatial tasks are also good at mathematics questions. We also know that some of the same parts of the brain that are used for spatial thinking are also activated when we do mathematics. The good news is that many studies have shown that you can improve your spatial thinking through "training." This means that practicing spatial games and doing spatial activities can improve your spatial performance. In this article we discuss ways by which you can improve your spatial thinking and we look at evidence that suggests that spatial training may also improve mathematics.

\section{INTRODUCTION}

How do you know how to organize objects, such as packing a suitcase or fitting your books into your schoolbag? How do you know to put 
Figure 1

Sample mental rotation task.

\section{SPATIAL THINKING}

How the brain processes the position and shape of different objects.

\section{MATHEMATICS}

A subject relating to number and quantities.

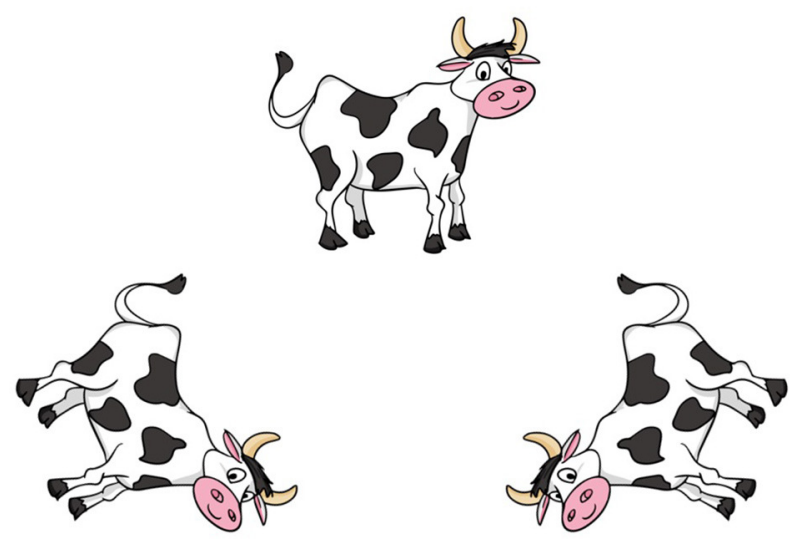

Figure 1

your shoes on the right feet and how to button your shirt correctly? How do you find your way around a shopping center, and how do you know what to do if you get off the bus at the wrong stop? These tasks all rely on spatial abilities. People depend on their spatial thinking abilities hundreds of times every day without noticing. Even beyond everyday activities, most people, including teachers, do not realize that spatial thinking can influence how well you do in school, especially in mathematics classes. So, what is spatial thinking, and is it possible to become an expert spatial thinker?

\section{SPATIAL THINKING: HOW DO WE MEASURE IT?}

We use spatial thinking to understand the location (position) and dimensions (such as length and size) of objects, and how different objects are related to each other. It is important to understand that spatial thinking is not just one skill, but a set of different skills. Some of the most important spatial skills, and the tests scientists use to measure them, are described below.

\section{Mental Rotation}

Mental rotation allows us to turn (manipulate) images in our heads. You can try an example if you close your eyes and imagine an object like a car. Now, can you imagine what the car would look like if it was turned upside down? To do this you have to use mental rotation. In Figure 1, you can see a mental rotation test. Can you choose which picture on the bottom is the same as the picture on the top? To figure this out, you must turn the cows in your head. Then you can tell that the cow on the left is the same as the cow above it. No matter how much you turn the cow on the right, it will always be facing the wrong direction. Completing this test requires mental rotation. It is not only possible to turn objects in your head, you can also imagine what an object would look like if it was broken in half, folded, or bent. 
Figure 2

Sample disembedding task.

\section{Disembedding}

Disembedding skills are the spatial skills needed to separate one object or picture from a more complicated background. This allows us to understand how complicated structures are made up from separate parts. A very simple example of this is shown in Figure 2. Can you find the orange shape in the more complicated image?

\section{Spatial Scaling}

Spatial scaling is the ability to transform information between representations of different sizes. For example, spatial scaling is needed to be able to understand that the picture of a park you see on the map on your phone represents the same park that you are standing in. Another example is when we assemble furniture like a wardrobe using paper instructions with small diagrams. To build the wardrobe you must be able understand that the small picture of a wardrobe door in the diagram represents the life-size door that you have unpacked and need to assemble. In each picture in Figure 3 , there is a ball positioned between two trees. Which picture on the bottom is the same as the one on the top? You will notice that the two pictures on the bottom are not the same size as the one on the top. This means that you must use spatial scaling when comparing them (correct answer is left).

\section{Navigation}

Navigation skills are vital for moving around our environments and getting us to the places we need to go. To navigate properly you must be able to understand the relationships between buildings, to use landmarks, to imagine what streets or buildings will look like from different perspectives, to learn routes, and to establish an understanding of the layout of your environment. 
Figure 3

Sample spatial scaling task.

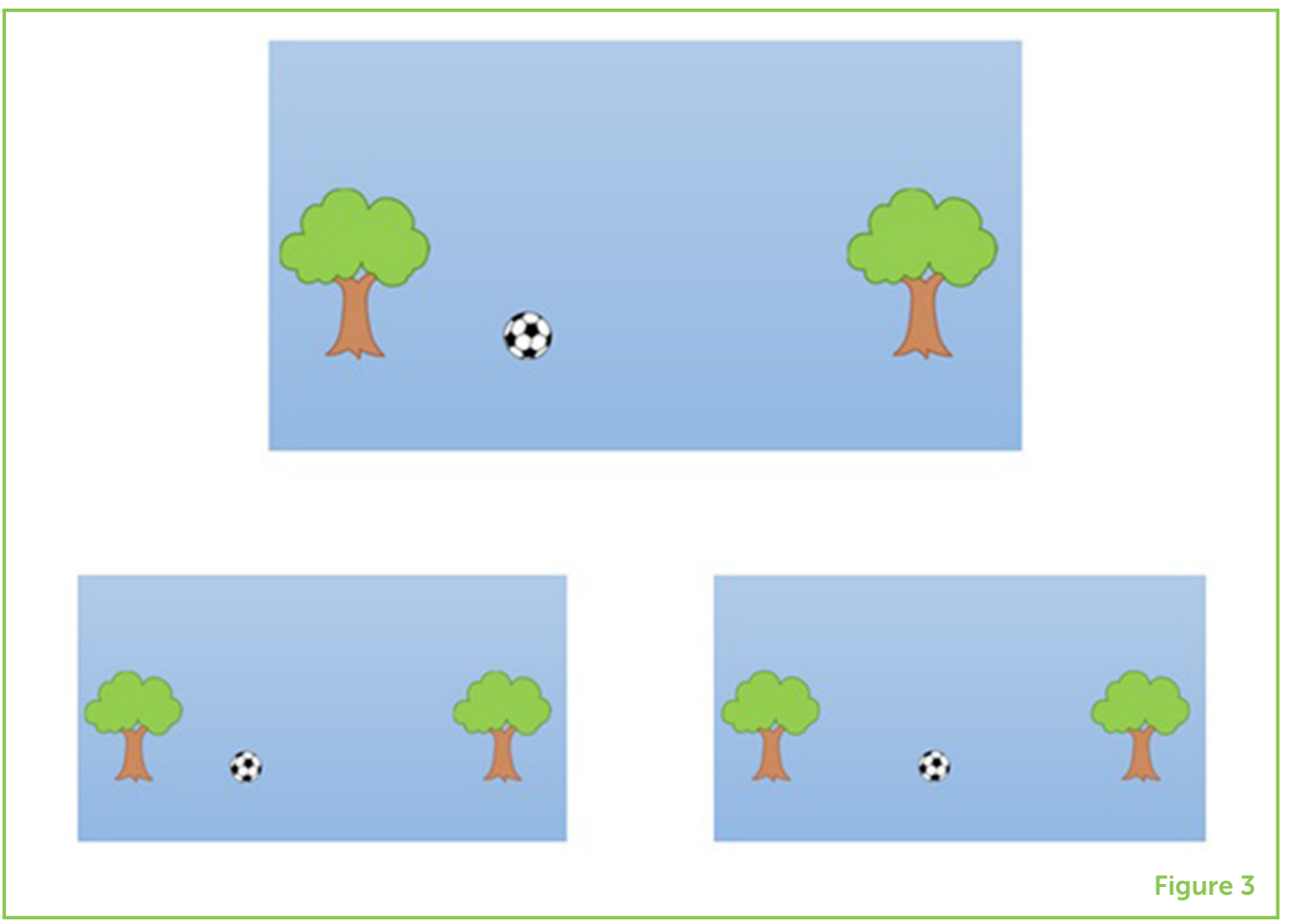

\section{SPATIAL THINKING IS IMPORTANT IN SCHOOL AND WORK}

Beyond its obvious importance in everyday life, it turns out that spatial thinking is also important for how well you do in school, particularly for mathematics lessons. People who are good at spatial thinking tasks also get high scores in mathematics tests. The link between good spatial thinking and good mathematics performance exists in people of different ages. For example, research has shown that infants who are better at constructing building blocks do better in counting and number tests [1]. For children in primary school, many researchers have shown that different types of spatial thinking are important for different mathematics tasks [2]. Children who are good at spatial scaling are also good at positioning numbers on a number line, and children who are good at mental rotation are better at doing calculation tasks with missing numbers like $3+\square=5$. For adults, having good spatial skills is very important for certain jobs. For example, engineers need spatial skills to visualize the structure of a bridge or building, geologists need spatial skills so that they can navigate landscapes, doctors need spatial skills to make sure that they give injections in the right position and to read x-rays properly, and biologists need spatial skills to understand how food moves through the different parts of our digestive system. Research shows that people who have good spatial skills when they are teenagers are more likely to have jobs in Science, Technology, Engineering, and Mathematics when they are adults. 


\section{COGNITIVE}

\section{TRAINING}

Practicing or rehearsing specific thinking skills with the intention of improving them.

\section{WHAT IF I AM NOT GOOD AT SPATIAL TASKS?}

The good news is that if you are someone who is not particularly good at spatial activities, you do not have to worry. Spatial thinking is one cognitive skill that seems to respond particularly well to being trained. Many research studies have attempted to improve spatial ability through different types of cognitive training. Although the word training is often associated with physical exercise, when cognitive (brain) scientists use the word training, they usually mean practice. This means that "Spatial Training" usually involves practicing paper and pencil spatial tasks, completing spatial games on a computer, or doing spatial activities like building structures with blocks. Many studies have shown that if you practice, your spatial thinking can be improved [3].

The even better news comes from new research that shows that if you improve your spatial thinking, you also improve in mathematics tests. When training in one skill leads to improvements in another, it is called transfer. Studies on other types of thinking show that it is very difficult to get brain training to transfer to untrained skills. You can read about other types of brain training and whether they work here [7]. Therefore, spatial training is quite unusual and important as there is evidence that training spatial thinking does transfer to other skills, for example mathematics.

Recent research that I completed showed that children obtained higher scores on a mathematics test after they watched a short video on spatial thinking [4]. Other researchers have also shown that using tangrams, which are a type of jigsaw puzzle, and other spatial games can improve mathematics skills [5]. Unfortunately, spatial thinking is not usually taught in schools. However, there are many ways that you can easily introduce it into your life at home and in school. This includes using more diagrams and graphs to help you when you are learning new topics in school, using more spatial language, including words like above, over, around, through, parallel, symmetrical, and gestures when you are explaining difficult ideas to your friends or younger siblings, practicing constructing things with blocks, Lego or puzzles, putting together furniture or even wrapping presents. It is also possible that some computer games like Minecraft (where players must use 3-D blocks to build structures like houses and cities) or games that require players to navigate mazes or unfamiliar spaces, might also improve spatial thinking.

\section{WHY IS SPATIAL THINKING IMPORTANT FOR MATHEMATICS?}

As researchers, one question that we are still trying to answer is why spatial and mathematics skills are linked. In other words, why are people who are good at spatial thinking also good at mathematics? 
One possibility is that the same parts of the brain that we use for spatial tasks are also used for mathematics. One way to see what parts of the brain are activated (turned on) when we do specific types of activities is through functional Magnetic Resonance Imaging (fMRI). This technique uses a scanner that shows what parts of the brain are active at different times. For example, it can be used to tell what part of the brain becomes active when we do a mathematics activity. Research shows that some spatial and mathematics skills both rely on a similar part of the brain, the parietal lobe [6]. This means that training programs that encourage us to use spatial thinking might strengthen the connections between neurons (brain cells) in this part of the brain. This would be helpful for both spatial thinking and mathematics.

\section{CONCLUSION}

The next time you are trying to squeeze as many clothes as you can into your suitcase, or you are carefully following the map on your phone, remember how valuable your spatial abilities are. Perhaps even more than literacy and numeracy skills, spatial thinking abilities have a huge impact on how we get around and function in our day to day lives. Additionally, as outlined in this article, taking more opportunities to practice our spatial thinking might also improve our mathematics skills. Let us make space to develop our spatial thinking!

\section{ACKNOWLEDGMENTS}

We would like to wholeheartedly thank those who assisted in the translation of the articles in this Collection to make them more accessible to kids outside English-speaking countries, and for the Jacobs Foundation for providing the funds necessary to translate the articles. For this article, we would especially like to thank Nienke van Atteveldt and Sabine Peters for the Dutch translation.

\section{ORIGINAL SOURCE ARTICLE}

Gilligan, K. A., Hodgkiss, A., Thomas, M. S., and Farran, E. K. 2019. The developmental relations between spatial cognition and mathematics in primary school children. Dev. Sci. 22:e12786. doi: 10.1111/desc. 12786

\section{REFERENCES}

1. Verdine, B. N., Golinkoff, R. M., Hirsh-Pasek, K., Newcombe, N. S., Filipowicz, A. T., and Chang, A. 2014. Deconstructing building blocks: preschoolers' spatial assembly performance relates to early mathematical skills. Child Dev. 85:1062-76. doi: 10.1111/cdev.12165 
2. Mix, K. S., Levine, S. C., Cheng, Y.-L., Young, C., Hambrick, D. Z., Ping, R., et al. 2016. Separate but correlated: the latent structure of space and mathematics across development. J. Exp. Psychol. Gen. 145:1206-27. doi: 10.1037/xge00 00182

3. Uttal, D. H., Meadow, N. G., Tipton, E., Hand, L. L., Alden, A. R., Warren, C., et al. 2013. The malleability of spatial skills: a meta-analysis of training studies.

Psychol. Bull. 139:352-402. doi: 10.1037/a0028446

4. Gilligan, K. A., Thomas, M. S. C., and Farran, E. K 2019. First demonstration of effective spatial training for near-transfer to spatial performance and far-transfer to a range of mathematics skills at 8 years. Dev. Sci. e12909. doi: 10.1111/desc. 12909

5. Cheng, Y. L., and Mix, K. S. 2014. Spatial training improves children's mathematics ability. J. Cogn. Dev. 15:2-11. doi: 10.1080/15248372.2012.725186

6. Hawes, Z., Moriah Sokolowski, H., Ononye, C. B., and Ansari, D. 2019. Neural underpinnings of numerical and spatial cognition: An fMRI meta-analysis of brain regions associated with symbolic number, arithmetic, and mental rotation. Neurosci. Biobehav. Rev. 103:316-33. doi: 10.1016/j.neubiorev.2019.05.007

7. Goffin, C., and Ansari, D. 2018. Can brain training train your brain? Using the scientific method to get the answer. Front. Young Minds 6:26. doi: 10.3389/ frym.2018.00026

SUBMITTED: 01 October 2019; ACCEPTED: 26 March 2020;

PUBLISHED ONLINE: 08 May 2020.

EDITED BY: Stephan E. Vogel, University of Graz, Austria

CITATION: Gilligan KA (2020) Make Space: The Importance of Spatial Thinking for Learning Mathematics. Front. Young Minds 8:50. doi: 10.3389/frym.2020.00050

CONFLICT OF INTEREST: The author declares that the research was conducted in the absence of any commercial or financial relationships that could be construed as a potential conflict of interest.

COPYRIGHT @ 2020 Gilligan. This is an open-access article distributed under the terms of the Creative Commons Attribution License (CC BY). The use, distribution or reproduction in other forums is permitted, provided the original author(s) and the copyright owner(s) are credited and that the original publication in this journal is cited, in accordance with accepted academic practice. No use, distribution or reproduction is permitted which does not comply with these terms.

\section{YOUNG REVIEWER}

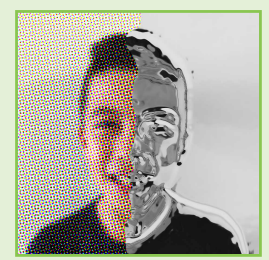

\section{GONI, AGE: 11}

I like reading, video games, and playing sports. I play soccer, basketball, fencing, and like running in cross country. My favorite food is pho or sushi. I like history, geography, and the study of animals. I play piano and know Hebrew, English, and I am learning Chinese. I just came back to the US from 1 year in Israel. 


\section{AUTHOR}

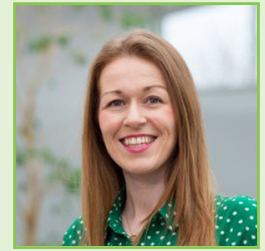

\section{KATIE A. GILLIGAN}

My research explores how children learn mathematics and in particular how spatial thinking plays a role in mathematics achievement. I am interested in developing different types of training to improve children's mathematics skills in the classroom, e.g., playing computer-games that use shapes and spatial thinking, watching videos that teach spatial strategies, playing with manipulatives like building blocks and lego.* k.gilliganasurrey.ac.uk 